\title{
Late toxicity and five year outcomes after high-dose-rate brachytherapy as a monotherapy for localized prostate cancer
}

\author{
Pirus Ghadjar ${ }^{*}$, Sebastian L Oesch², Cyrill A Rentsch³ ${ }^{3}$ Bernhard Isaak², Nikola Cihoric ${ }^{2}$, Peter Manser ${ }^{2}$,
} George N Thalmann ${ }^{4}$ and Daniel M Aebersold ${ }^{2}$

\begin{abstract}
Background: To determine the 5-year outcome after high-dose-rate brachytherapy (HDR-BT) as a monotherapy. Methods: Between 10/2003 and 06/2006, 36 patients with low (28) and intermediate (8) risk prostate cancer were treated by HDR-BT monotherapy. All patients received one implant and 4 fractions of 9.5 Gy within 48 hours for a total prescribed dose (PD) of 38 Gy. Five patients received concomitant androgen deprivation therapy (ADT). Toxicity was scored according to the common terminology criteria for adverse events from the National Cancer Institute (CTCAE) version 3.0. Biochemical recurrence was defined according to the Phoenix criteria and analyzed using the Kaplan Meier method. Predictors for late grade $3 \mathrm{GU}$ toxicity were analyzed using univariate and multivariate Cox regression analyses.

Results: The median follow-up was 6.9 years (range, 1.5-8.0 years). Late grade 2 and 3 genitourinary (GU) toxicity was observed in 10 (28\%) and 7 (19\%) patients, respectively. The actuarial proportion of patients with late grade 3 GU toxicity at 5 years was 17.7\%. Late grade 2 and 3 gastrointestinal (Gl) toxicities were not observed. The crude erectile function preservation rate in patients without ADT was 75\%. The 5 year biochemical recurrence-free survival (bRFS) rate was $97 \%$. Late grade $3 \mathrm{GU}$ toxicity was associated with the urethral volume $(p=0.001)$ and the urethral $V_{120}$ (urethral volume receiving $\geq 120 \%$ of the $P D ; p=0.0005$ ) after multivariate Cox regression.
\end{abstract}

Conclusions: After HDR-BT monotherapy late grade $3 \mathrm{GU}$ was observed relatively frequently and was associated with the urethral $V_{120}$. Gl toxicity was negligible, the erectile function preservation rate and the bRFS rate was excellent.

Keywords: Urogenital abnormalities, Radiotherapy, Toxicity, Prostatic neoplasms, Brachytherapy

\section{Background}

High-dose-rate brachytherapy (HDR-BT) offers the direct application of high doses to the prostate while sparing the surrounding bladder and rectum. It has also advantages over the permanent seed implantation (seeds or low-dose rate brachytherapy) regarding radiation safety and HDR-BT thus gained popularity both as a boost combined with additional external beam radiotherapy or as a monotherapy for localized prostate cancer.

Several groups have described their HDR-BT monotherapy experience [1-9], however less is known about the outcomes after longer follow-up. We therefore performed

\footnotetext{
*Correspondence: pirus.ghadjar@charite.de

'Department of Radiation Oncology, Charité Universitätsmedizin Berlin,

Augustenburger Platz 1, Berlin 13353, Germany

Full list of author information is available at the end of the article
}

an up-date of our previously reported HDR-BT monotherapy cohort [9].

\section{Methods}

\section{Patient selection and characteristics}

A total of 41 patients with histologically proven adenocarcinoma of the prostate treated by HDR-BT as a monotherapy were retrospectively analyzed. The pre-treatment staging included a complete history, physical examination, digital rectal examination, transrectal ultrasound (TRUS) of the prostate, biopsy with specification of the Gleason score, pre-treatment prostate-specific antigen (PSA) level, computed tomography $(\mathrm{CT})$ and/or magnetic resonance imaging (MRI) of the abdomen and pelvis as previously reported [9]. In the presence of bone pain a bone scan was performed. The indication for HDR-BT as a monotherapy 
was limited to low and intermediate risk prostate cancer, similar to criteria for low-dose-rate (LDR) seeds brachytherapy. Risk of recurrence was determined according to the National Comprehensive Cancer Network practice guidelines in oncology (www.nccn.org): Low risk being T1-T2a, Gleason score $\leq 6$, PSA $<10 \mathrm{ng} / \mathrm{mL}$ and intermediate risk being T2b-T2c or, Gleason score 7 or PSA $10-20 \mathrm{ng} / \mathrm{mL}$. Patients with prior pelvic radiation $(\mathrm{n}=1)$ and genitourinary $(\mathrm{GU})$ morbidity $\geq$ grade 2 prior to radiation $(\mathrm{n}=4)$ were excluded from further analysis. The remaining 36 patients, treated between October 2003 and June 2006, comprised the study population.

This study was approved by the institutional ethics committee of the Bern University Hospital.

\section{Androgen deprivation therapy}

A total of 5 patients (14\%) received androgen deprivation therapy (ADT) of which 3 were low and 2 were intermediate risk patients. ADT was initiated in all 5 patients by the referring urologist at their descretion for concommittant treatment. ADT was always given before and during brachytherapy, with a median total duration of 7 months (range, 3-33 months). One patient received combined androgen blockade consisting of antiandrogen and a gonadotropin releasing hormone analogue. Four patients received antiandrogen monotherapy.

\section{Brachytherapy implant}

All patients received one implant and four separate fractions of HDR-B, with a minimal interval of 6 hours delivered within 48 hours. Fraction dose was 9.5 Gy, the total prescribed dose (PD) was $38 \mathrm{~Gy}$, as previously described [9]. For the implantation of the applicators, patients underwent spinal anesthesia and were positioned in lithotomy position. The applicators were implanted transperineally by an urologist under real-time TRUS guidance using a template for parallel needle insertion. Patients received a variable number of needles, median 13 (range, 10-18) depending on the prostate size and configuration. Axial cross sections were acquired in $5 \mathrm{~mm}$ steps and transferred to the Plato $^{\circ}$ treatment planning software V14.2. (Nucletron, an Elektra company (Elektra AB, Stockholm, Sweden)). Dose optimization was done on the reconstructed applicator geometry using dose point and manual optimization algorithms. A typical ultrasound image of the applicator geometry is provided in Figure 1. Before radiation, patients received $2-3$ gold markers (diameter: $0.9 \mathrm{~mm}$, length: $7 \mathrm{~mm}$ ), implanted under TRUS guidance, which were used for assessment of inter-fraction needle motion, assessed by pelvic $\mathrm{x}$-ray before each fraction. In case of dislocation all applicators were repositioned before the next fraction until complete agreement was found with the reference $\mathrm{x}$-ray. A video capture software (Nucletron) was used to transfer the
US images to the Plato $^{\circ}$ treatment planning software. The prostate gland and the organs at risk (OAR) i.e. prostatic urethra and rectum were contoured. The dose to the rectum and urethra was evaluated using dose volume histogram (DVH). The contouring of the urethra and the rectum was based on the ultrasound image: the urethra was delineated from the apex of the prostate to the base of the bladder, the rectum was defined as the rectum sector on the ultrasound image along the planning target volume (PTV) including the muscularis propria.

The prostate without safety margins was defined as the PTV. Based on DVH analysis, the quality of plans and implants was evaluated using the following indicators: The PTV $V_{100}$ (\% of PTV receiving $\geq 100 \%$ of the PD) and $\mathrm{D}_{90}$ (dose delivered to $90 \%$ of the PTV), both of which were recorded. To assess dose exposure of OAR, the absolute values of $\mathrm{V}_{70}, \mathrm{~V}_{80}$ of the rectum and $\mathrm{V}_{100}$, $\mathrm{V}_{120}, \mathrm{~V}_{125}, \mathrm{~V}_{150}$ of the prostatic urethra were determined (volume of the OAR that received a dose $\geq 70 \%, 80 \%$ or $100 \%, 120 \%, 125 \%, 150 \%$ of the PD, respectively). Additionally, the maximum dose $\mathrm{D}_{1}$ of the rectum and urethra (defined as the dose that encompass $\geq 1 \%$ of the rectal or urethral volume) and the number of needles used was recorded. The dosimetry optimization goals were to achieve a most conformal as possible coverage of the prostate taking into consideration sometimes an under dosage in apex and base regions and at the same time optimizing the dwell times to prevent locally very high dose values. A hard constraint was: PTV $\mathrm{V}_{100}>90 \%$. The max dose on the rectum was required to be less then $80 \%\left(\mathrm{~V}_{80}=0\right)$ of the prescribed dose and the maximal dose for the urethra less than $150 \%\left(\mathrm{~V}_{150}=0\right)$ of the prescribed dose. The total dose was prescribed to the $100 \%$ isodose covering the PTV. A high-dose-rate afterloading system (Nucletron) with a ${ }^{192}$ Ir stepping source was used.

\section{Follow-up protocol}

Follow-up visits were arranged 2-4 weeks after completion of HDR-BT and every 3 to 6 months for the first 2 years and annually thereafter with a digital rectal examination and a serum PSA level obtained at each visit. Patients alternated follow-up visits between their urologist and radiation oncologist. None of the patients were lost to follow-up.

\section{Toxicity scoring}

The symptoms dysuria, incontinence, retention, frequency/ urgency, hematuria, diarrhea, rectal pain and rectal bleeding were graded using the common terminology criteria for adverse events from the National Cancer Institute (CTCAE version 3.0). Erectile dysfunction (ED) was scored based on clinical symptoms as follows: grade $0=$ no symptoms of ED; grade $1=$ decreased erectile function but still able to perform sexual intercourse; grade $2=$ decreased erectile function not able to perform 


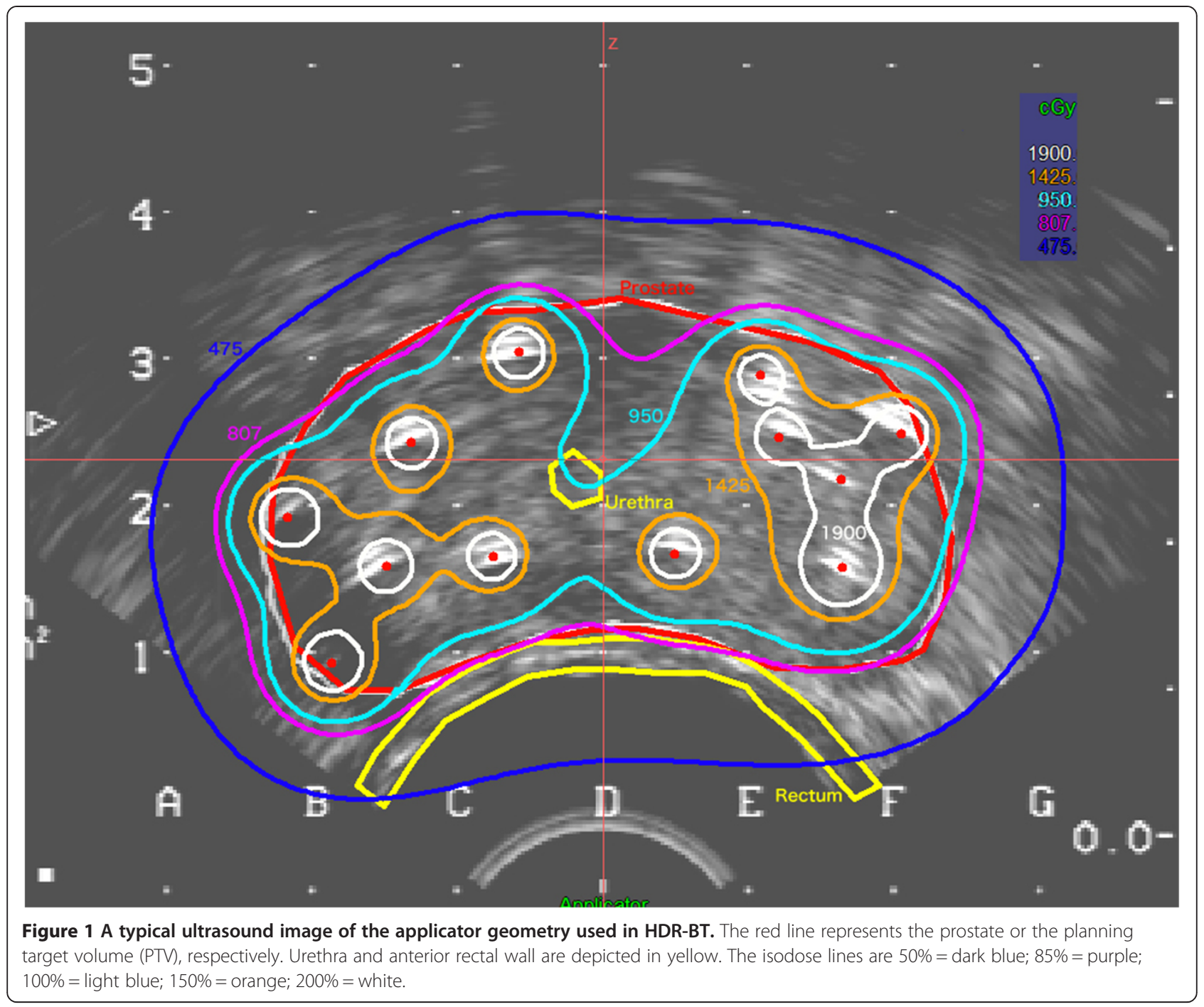

intercourse; grade $3=$ no erections. Late toxicity was defined as symptoms who increased over baseline and occurred within 3 months after the end of treatment. Late toxicity at last follow-up visit was noted and termed "last late toxicity"; this was done to assess whether the late toxicity was persistent or was transient.

\section{Biochemical failure}

Biochemical recurrence-free survival (bRFS) was assessed according to the Phoenix criteria, defining a biochemical failure as a PSA rise of $2 \mathrm{ng} / \mathrm{mL}$ or more above the nadir PSA.

\section{Statistical analysis}

Descriptives include absolute and relative frequencies for categorical variables and the median and interquartile range (IQR) for quantitative variables.
The primary objective was the occurrence of late grade 3 GU toxicity and secondary objectives included bRFS and late gastrointestinal (GI) toxicity. Late GU toxicity (grade 0-2 vs. grade 3) was grouped according to the number of grade 3 events observed and compared with clinical and dosimetric factors using univariate and multivariate Cox regression analyses. Actuarial toxicity-free survival and bRFS rates were calculated using the Kaplan Meier method. Statistical significance was considered on a two-sided significance level $(\alpha)$ of $=0.05$. Statistical analysis was performed with $\mathrm{SPSS}^{\oplus}$ version 19.0 (SPSS Inc., Chicago, IL).

\section{Results and discussion}

Patient characteristics are summarized in Table 1 . The pre-implant prostate size was $40 \mathrm{~cm}^{3}$ (range, 24-62 $\mathrm{cm}^{3}$ ), however this information was only available for 17/36 patients. Dosimetric characteristics are summarized in 


\section{Table 1 Patient characteristics}

\begin{tabular}{lc}
\hline Total patients & ( $\mathbf{n}=\mathbf{3 6})$ \\
\hline Age, median (IQR), years & $63(10)$ \\
Tumor classification & \\
CT1 & $27(75.0 \%)$ \\
CT2 & $9(25.0 \%)$ \\
Gleason Score & \\
$3-5$ & $8(22.2 \%)$ \\
6 & $23(63.9 \%)$ \\
7 & $5(13.9 \%)$ \\
Pre-treatment PSA & \\
$\leq 10$ ng/mL & $31(86.1 \%)$ \\
$>10$ ng/mL & $5(13.9 \%)$ \\
Percent positive biopsies & \\
$\leq 50 \%$ & $17(47.2 \%)$ \\
$>50 \%$ & $14(38.9 \%)$ \\
Unknown & $5(13.9 \%)$ \\
Risk group & \\
Low & $28(77.8 \%)$ \\
Intermediate & $8(22.2 \%)$ \\
\hline Abbreviations: PSA prostate-specific antigen, IQR interquartile range. &
\end{tabular}

Table 2. The median follow-up was 6.9 years (range, $1.5-8.0$ years).

\section{Late genitourinary and gastrointestinal toxicity}

Baseline symptoms, acute toxicity and early late toxicity was previously described. Regarding GU baseline symptoms, these were completely absent in around $53 \%$, and were of grade 1 in $47 \%$ of the patients. GI baseline symptoms were absent in around $91 \%$ and of grade 1 and 2 in $3 \%$ and $6 \%$ of the patients, respectively [9]. Late GU toxicity was of grade 2 in $10(28 \%)$ and of grade 3 in

Table 2 Dosimetric characteristics

\begin{tabular}{lcc}
\hline Dosimetric measure & Mean (SD) & Median (IQR) \\
\hline PTV $V_{100}(\%)$ & $93.5(5.7)$ & $95.5(8.7)$ \\
PTV $D_{90}(\mathrm{~Gy})$ & $38.8(7.3)$ & $41.2(5.3)$ \\
Urethra $\mathrm{V}_{100}\left(\mathrm{~cm}^{3}\right)$ & $0.46(0.18)$ & $0.44(0.18)$ \\
Urethra $\mathrm{V}_{120}\left(\mathrm{~cm}^{3}\right)$ & $0.16(0.14)$ & $0.15(0.23)$ \\
Urethra $\mathrm{V}_{125}\left(\mathrm{~cm}^{3}\right)$ & $0.08(0.09)$ & $0.03(0.14)$ \\
Urethra $\mathrm{V}_{150}\left(\mathrm{~cm}^{3}\right)$ & $0.0(0.0)$ & $0.0(0.0)$ \\
Rectal $\mathrm{V}_{70}\left(\mathrm{~cm}^{3}\right)$ & $0.1(0.1)$ & $0.08(0.005)$ \\
Rectal $\mathrm{V}_{80}\left(\mathrm{~cm}^{3}\right)$ & $0.006(0.02)$ & $0.00(0.005)$ \\
\hline AbbreVatons:
\end{tabular}

Abbreviations: IQR interquartile range, $P T V$ planning target volume, $P T V V_{100}$ percentage of PTV receiving $\geq 100 \%$ of prescribed dose, $D_{90}$ dose administered to $90 \%$ of the PTV, urethral $V_{100}-V_{150}$ absolute urethral volume that received a dose $\geq 100 \%, 120 \%, 125 \%, 150 \%$ of the prescribed dose, rectal $V_{70}-V_{80}$ absolute rectal volume that received a dose $\geq 70 \%$ or $80 \%$, of the prescribed dose.
7 (19\%) (Table 3). The median time from RT completion to the occurrence of late grade $3 \mathrm{GU}$ toxicity was 77 months (IQR, 41.45 months). The 5 year probability of late grade $3 \mathrm{GU}$ toxicity was $17.7 \%$ (Figure $2 \mathrm{~A}$ ). All 7 patients who developed late grade $3 \mathrm{GU}$ toxicity underwent an urological intervention. Six patients had a bulbar urethral stricture requiring urethral dilatation, in 4 patients an additional TUR-P was performed. The remaining patient presented with acute urinary retention and received a foley catheter and underwent a TUR-P shortly thereafter. Late GU toxicity decreased as time from treatment completion elapsed. At the last follow-up visit late grade $3 \mathrm{GU}$ toxicity was not observed (Table 3).

No patient had late grade 2 or 3 GI toxicity at the last follow-up visit all grade 1 late GI toxicities were ameliorated (Table 4).

\section{Factors associated with genitourinary toxicity}

There was no association between late $\geq$ grade $2 \mathrm{GU}$ toxicity and clinical or dosimetric factors. However the occurrence of late grade $3 \mathrm{GU}$ toxicity was associated with clinical and dosimetric variables after univariate Cox regression analysis (Table 5 ). Late grade $3 \mathrm{GU}$ toxicity was associated with the urethral volume $(p=0.001)$ and

Table 3 Late genitourinary toxicity

\begin{tabular}{lccc}
\hline Symptom & Grade & $\begin{array}{c}\text { Late }^{\dagger} \\
\mathbf{n}(\%)\end{array}$ & $\begin{array}{c}\text { Last late }^{\text {( }} \\
\mathbf{n}(\%)\end{array}$ \\
\hline Dysuria & 0 & $23(64)$ & $36(100)$ \\
Incontinence & 1 & $8(22)$ & $0(0)$ \\
Retention & 2 & $5(14)$ & $0(0)$ \\
& 0 & $29(81)$ & $33(92)$ \\
Frequency/urgency & 1 & $7(19)$ & $3(8)$ \\
& 0 & $19(53)$ & $27(75)$ \\
& 1 & $3(9)$ & $6(17)$ \\
Hematuria & 2 & $7(19)$ & $3(8)$ \\
& 3 & $7(19)$ & $0(0.0)$ \\
Highest GU* & 0 & $16(44)$ & $25(70)$ \\
& 1 & $13(36)$ & $7(19)$ \\
& 2 & $6(17)$ & $4(11)$ \\
& 3 & $1(3)$ & $0(0.0)$ \\
& 0 & $28(78)$ & $34(94)$ \\
& 1 & $4(11)$ & $1(3)$ \\
& 2 & $4(11)$ & $2(3)$ \\
& 0 & $11(31)$ & $21(58)$ \\
& 1 & $10(28)$ & $6(25)$ \\
& 2 & $7(19)$ & $0(0)$ \\
\hline
\end{tabular}

Abbreviations: GU genitourinary, ${ }^{*}$ The highest toxicity in a patient was counted as a single event, ${ }^{\dagger}>3$ months after completion of therapy,

${ }^{\S}$ Incidence of late toxicity at last follow-up visit. 

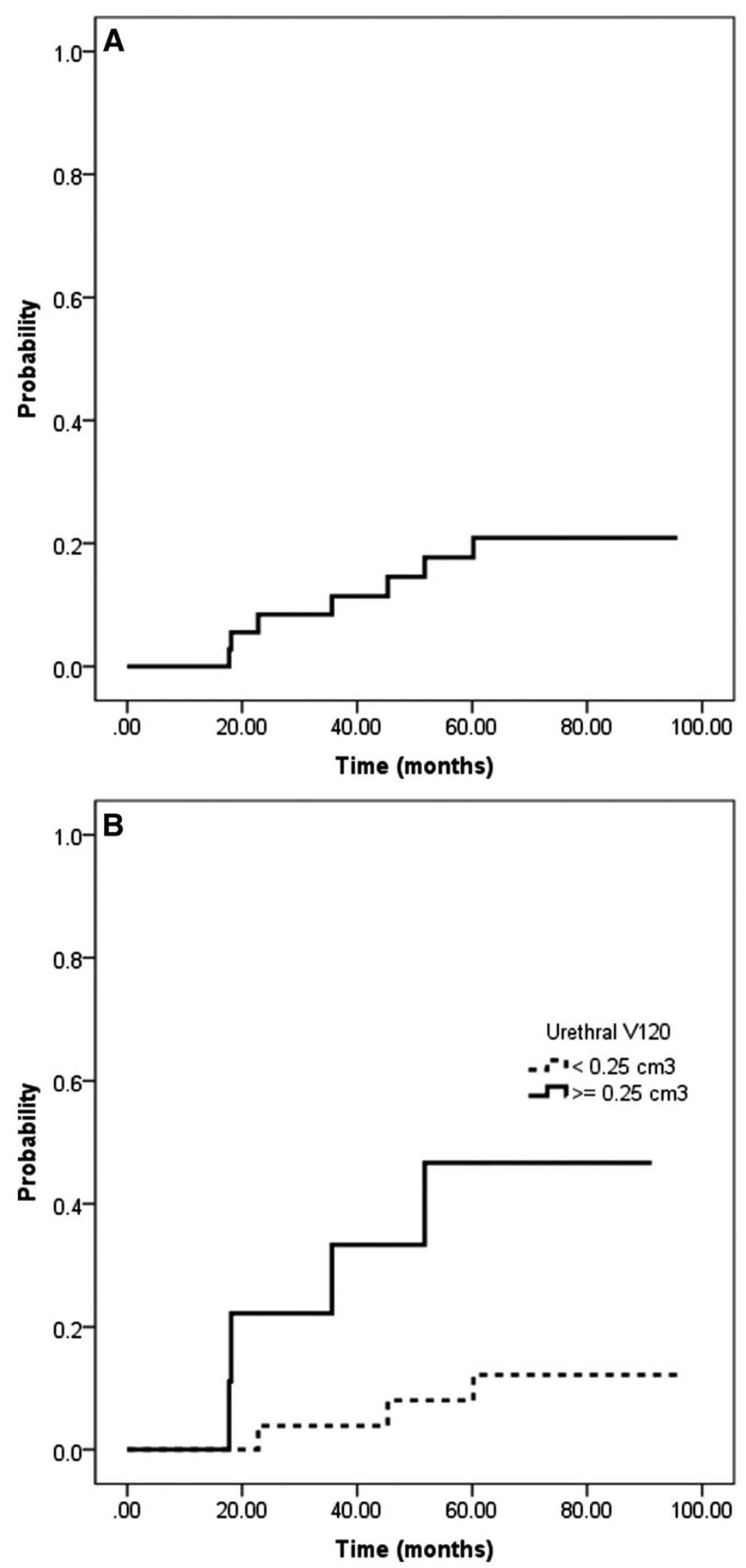

Figure 2 Kaplan Meier plots showing the probability of late grade 3 genitourinary toxicity for all patients (A) and stratified according to the urethral $\mathrm{V}_{120}$ (B). 
Table 4 Late gastrointestinal toxicity

\begin{tabular}{lccc}
\hline Symptom & Grade & $\begin{array}{c}\text { Late }^{\dagger} \\
\mathbf{n}(\%)\end{array}$ & $\begin{array}{c}\text { Last late }^{\S} \\
\mathbf{n}(\%)\end{array}$ \\
\hline Diarrhea & 0 & $33(92)$ & $36(100)$ \\
& 1 & $3(8)$ & $0(0)$ \\
Rectal pain & 2 & $0(0)$ & $0(0)$ \\
Rectal bleeding & 0 & $36(100)$ & $36(100)$ \\
Highest Gl* & 1 & $0(0.0)$ & $0(0.0)$ \\
& 0 & $36(100)$ & $36(100)$ \\
& 1 & $0(0)$ & 0 \\
& 0 & $33(92)$ & $36(100)$ \\
\hline
\end{tabular}

Abbreviations: Gl gastrointestinal, *The highest toxicity in a patient was counted as a single event, ${ }^{\dagger}>3$ months after completion of therapy, Incidence of late toxicity at last follow-up visit.

the urethral $V_{120}$ (urethral volume receiving $\geq 120 \%$ of the prescribed dose; $p=0.0005)$ after multivariate Cox regression (Table 4). The quartiles for the urethral $\mathrm{V}_{120}$ were $25 \%=0.02 \mathrm{~cm}^{3} ; 50 \%=0.15 \mathrm{~cm}^{3}$ and $75 \%=0.25 \mathrm{~cm}^{3}$. The probability of late grade $3 \mathrm{GU}$ toxicity stratified to the
$75 \%$ quartile of the urethral $\mathrm{V}_{120}$ is depicted in Figure 2B. Significant correlations between the urethral V100, V120 and V125 and increased PTV V100 and D90, respectively have previously been described [9].

\section{Erectile function}

Of the 31 patients who did not receive ADT, 20 (65\%) had no symptoms of ED before treatment and 8 (26\%) had decreased erectile function but were still able to perform sexual intercourse. The remaining three patients had decreased erectile function and were unable to perform intercourse. At the latest follow-up visit 21 of these 28 patients $(75 \%)$ were able to perform intercourse. Thus, the erectile function preservation rate was $75 \%$ in patients without ADT. Of these 21 sexually active men 7 patients received oral therapy with a phosphodiesterase type 5 inhibitor.

\section{Biochemical outcome}

During follow-up one patient with low-risk disease who did not receive ADT experienced biochemical recurrence after 56 months. The 5 year bRFS according to the Phoenix criteria was $97 \%$. Overall the median PSA nadir value was $0.1 \mathrm{ng} / \mathrm{mL}$ (IQR, $0.235 \mathrm{ng} / \mathrm{mL}$ ) and time to nadir was

Table 5 Univariate and multivariate associations with late grade 3 genitourinary toxicity

\begin{tabular}{|c|c|c|c|}
\hline \multirow[t]{2}{*}{ Variables } & \multirow[t]{2}{*}{ Associated level } & \multicolumn{2}{|c|}{ Late grade $3 \mathrm{GU}$ toxicity } \\
\hline & & Hazard ratio $(95 \% \mathrm{Cl})$ & p-value \\
\hline \multicolumn{4}{|l|}{ Univariate analysis } \\
\hline Age (years) & Continuous & $1.031(0.921-1.154)$ & 0.596 \\
\hline Risk group* & Intermediate & $0.659(0.079-5.481)$ & 0.699 \\
\hline Prostate volume ${ }^{\#}$ & Continuous & $0.928(0.835-1.032)$ & 0.170 \\
\hline Number of Applicators & Continuous & 1.247 (0.906-1.718) & 0.176 \\
\hline PTV volume $\left(\mathrm{cm}^{3}\right)$ & Continuous & $1.014(0.974-1.056)$ & 0.504 \\
\hline PTV V ${ }_{100}(\%)$ & Continuous & $>1000(0.000->1000)$ & 0.371 \\
\hline PTV D $D_{90}(G y)$ & Continuous & 83.476 (0.019- > 1000) & 0.301 \\
\hline Urethral volume $\left(\mathrm{cm}^{3}\right)$ & Continuous & $41.143(2.754-614.621)$ & 0.007 \\
\hline Urethral $D_{1}(G y)$ & Continuous & $6.946(0.000->1000)$ & 0.692 \\
\hline Urethral $V_{100}\left(\mathrm{~cm}^{3}\right)$ & Continuous & $183.29(6.785->1000)$ & 0.002 \\
\hline Urethral $V_{120}\left(\mathrm{~cm}^{3}\right)$ & Continuous & $926.461(2.653->1000)$ & 0.022 \\
\hline Urethral $\bigvee_{125}\left(\mathrm{~cm}^{3}\right)$ & Continuous & 405.747 (0.249- > 1000) & 0.111 \\
\hline Acute grade $3 \mathrm{GU}$ toxicity & Yes & $7.846(0.876-70.307)$ & 0.066 \\
\hline \multicolumn{4}{|l|}{ Multivariate analysis } \\
\hline Urethral volume $\left(\mathrm{cm}^{3}\right)$ & Continuous & $338.940(9.502->1000)$ & 0.001 \\
\hline Urethral $\bigvee_{100}\left(\mathrm{~cm}^{3}\right)$ & Continuous & - & \\
\hline Urethral $V_{120}\left(\mathrm{~cm}^{3}\right)$ & Continuous & $5778.111(14.398->1000)$ & 0.005 \\
\hline Acute grade $3 \mathrm{GU}$ toxicity & Yes & - & \\
\hline
\end{tabular}

Abbreviations: GU genitourinary, PTV planning target volume, PTV $V_{100}$ percentage of PTV receiving $\geq 100 \%$ of prescribed dose, $D_{90}$ dose administered to $90 \%$ of the PTV, Urethral $V_{100}-V_{150}$ absolute urethral volume that received a dose $\geq 100 \%, 120 \%, 125 \%, 150 \%$ of the prescribed dose, Urethral $D_{1}$ maximal dose that encompass $1 \%$ of the urethral volume, *according to the National Comprehensive Cancer Network (NCCN), "\#pre-treatment, ADT androgen deprivation therapy. 
61.6 months (IQR, 42.24 months). During follow-up two patients died, both in the absence of biochemical recurrence, thus the crude overall survival rate was $94 \%$.

This report describes the 5-year late toxicity and bRFS outcome, based on a median follow-up of almost seven years, in association with DVH parameters in patients with low and intermediate risk prostate cancer treated by HDR-BT monotherapy.

We are aware of 5 cohorts of patients treated by HDR-BT as a monotherapy using more than 3 fractions and reporting on late toxicity and biochemical control data (Table 6) [1-5].

Meanwhile, further reports on extreme HDR-BT hypofractionation using only 3 [6] 2 [7] or only 1 fraction [8] became available with promising results regarding cancer control and acute and early late toxicity. However, due to their relatively short median follow-up of $<40$ months, these results must be regarded as preliminary.

Compared to the mentioned literature the biochemical control rate of $97 \%$ in our low-intermediate-risk patient cohort was excellent, the erectile function preservation rate of $75 \%$ after almost 7 years of follow-up was encouraging and late GI toxicity was negligible. However the observed late GU grade 2 and 3 toxicity rates of 28 and $19 \%$ were in the upper range of published studies. Remarkably, some of the grade 2 events were transient and resolved until the end of follow-up were the incidence of late grade 2 toxicity was $17 \%$. Moreover, all grade 3 events were successfully managed by urethral dilatation followed by a TUR-P in 4 of 6 cases. We found an association between late grade 3 toxicity and the urethral $\mathrm{V}_{120}$ after multivariate analysis. The association between the dose to the prostatic urethra and the occurrence of bulbar urethral strictures might be indirectly caused by radiation of vascular support of the urethra. Uncertainties of the delineation of the urethra without use of hydrogel might also have contributed to excess dose to the urethra.

We used only one implant for the 4 fractions applied over 2 days and controlled interfractional movement of the applicators using pre-implanted gold markers and orthogonal conventional X-rays. As previously described significant applicator shifts were detected and corrected and these shifts were not associated with the occurrence of GU toxicity [10]. However, we cannot exclude that some applicator shifts were not recognized contributing to impaired dosimetry and subsequently late GU toxicity. Also, during planning the rectal ultrasound probe was in place with legs up in lithotomy position while treatment was delivered with legs straight and without ultrasound probe which has been described as unfeasible by others [11]. The conduction of 2 separate implants might reduce late GU toxicity and improved image-guided procedures in brachytherapy could help to limit these effects, in future. Moreover, patients were not assessed with the International Prostate Symptom Score (IPSS) at baseline. It might be that exclusion of patients with significant baseline symptoms according to the IPSS would have reduced the need for urological interventions in our cohort. Also the use of Cox regression analysis is limited because of the small sample size and low number of events. As a note of caution, we have also to emphasize that the median follow-up time of present study is the longest reported so far. It might well be, that the grade 3 toxicities will increase in other patients cohorts with longer follow-up time. Additionally, it must be acknowledged that most of the low-risk patients in our cohort might alternatively have been treated by an active surveillance approach which might be associated with comparable tumor control rates but less GU toxicity [12] - a concept, however, which was not well established at that time.

Table 6 Study results on HDR-BT as a monotherapy using more than 3 fractions

\begin{tabular}{|c|c|c|c|c|c|c|c|c|c|c|c|}
\hline Study (reference) & $\mathrm{n}$ & $\begin{array}{l}\text { M. follow-up } \\
\text { (vrs) }\end{array}$ & Risk & HDR schedule & ADT & $\begin{array}{l}\text { Toxicity } \\
\text { score }\end{array}$ & $\begin{array}{l}\text { G2 GI late } \\
\text { toxicity }\end{array}$ & $\begin{array}{l}\text { G3 GI late } \\
\text { toxicity }\end{array}$ & $\begin{array}{l}\text { G2 GU late } \\
\text { toxicity }\end{array}$ & $\begin{array}{l}\text { G3 GU late } \\
\text { toxicity }\end{array}$ & bRFS* \\
\hline \multirow[t]{2}{*}{ Demanes (1) } & \multirow[t]{2}{*}{298} & \multirow[t]{2}{*}{5.2} & \multirow{2}{*}{$\begin{array}{l}\text { L } 81 \%, \text { I 18\%, } \\
\text { H 1\% }\end{array}$} & $6 \times 7$ Gy $(53 \%)$ & \multirow[t]{2}{*}{$24 \%$} & \multirow[t]{2}{*}{ CTCAE 3.0} & \multirow[t]{2}{*}{$<1 \%$} & \multirow[t]{2}{*}{$<1 \%$} & \multirow[t]{2}{*}{$10 \%$} & \multirow[t]{2}{*}{$3 \%$} & \multirow[t]{2}{*}{$97 \%$} \\
\hline & & & & 4 × 9.5 Gy $(47 \%)$ & & & & & & & \\
\hline \multirow[t]{2}{*}{ Zamboglou (2) } & \multirow[t]{2}{*}{718} & \multirow[t]{2}{*}{4.4} & \multirow{2}{*}{$\begin{array}{l}\text { L 55\%, I 25\%, } \\
\text { H 20\% }\end{array}$} & 4 × 9.5 Gy $(68 \%)$ & \multirow[t]{2}{*}{$21.4 \%$} & \multirow[t]{2}{*}{ CTCAE 3.0} & \multirow[t]{2}{*}{$\sim 1 \%$} & \multirow[t]{2}{*}{$1.6 \%$} & \multirow[t]{2}{*}{$\sim 20 \%$} & \multirow[t]{2}{*}{$3.5 \%$} & \multirow[t]{2}{*}{$94 \%$} \\
\hline & & & & 3 × 11.5 Gy $(32 \%)$ & & & & & & & \\
\hline Yoshioka (3) & 112 & 5.4 & $\begin{array}{l}\text { L 13\%, I 26\%, } \\
\text { H } 61 \%\end{array}$ & $9 \times 6$ Gy & $84 \%$ & CTCAE 3.0 & $12 \%^{\#}$ & $3 \%{ }^{\#}$ & $12 \%{ }^{\#}$ & $3 \%{ }^{\#}$ & $83 \%$ \\
\hline \multirow[t]{4}{*}{ Hoskin (4) } & \multirow[t]{4}{*}{197} & \multirow[t]{4}{*}{$0.5-5$} & \multirow{4}{*}{$\begin{array}{l}\text { L 4\%, I 52\%, } \\
\text { H } 44 \%\end{array}$} & 4 × 8.5 Gy $(15 \%)$ & \multirow[t]{4}{*}{$80 \%$} & \multirow[t]{4}{*}{ RTOG } & \multirow[t]{4}{*}{$1 \%$} & \multirow[t]{4}{*}{$4-13 \%$} & \multirow[t]{4}{*}{$20-30 \%$} & \multirow[t]{4}{*}{$3-14 \%$} & \multirow[t]{4}{*}{$95 \%$} \\
\hline & & & & 4 × 9 Gy (13\%) & & & & & & & \\
\hline & & & & 3 × 10.5 Gy (55\%) & & & & & & & \\
\hline & & & & 2 × 13 Gy (17\%) & & & & & & & \\
\hline Rogers (5) & 284 & 2.7 & | 100\% & $6 \times 6.5 \mathrm{~Gy}$ & $16 \%$ & RTOG & $0 \%$ & $0 \%$ & $1.8 \%$ & $0.7 \%$ & $83 \%$ \\
\hline Present study & 36 & 6.9 & L 78\%, I 22\% & $4 \times 9,5 \mathrm{~Gy}$ & $14 \%$ & CTCAE 3.0 & $0 \%$ & $0 \%$ & $28 \%$ & $19 \%$ & $97 \%$ \\
\hline
\end{tabular}

Abbreviations: $M$ median, $G$ grade, GU genitourinary, $G$ l gastrointestinal, $L$ low, I intermediate, $H$ high, $b R F S$ biochemical recurrence-free survival, *according to the Phoenix criteria, "genitourinary and gastrointestinal toxicity not discriminated. 


\section{Conclusions}

Late grade $3 \mathrm{GU}$ toxicity occurred in 19\% of patients. Proper patient selection, reduction of urethral dose (V120 below $0.25 \mathrm{~cm}^{3}$ ) along with a rigourous quality management including proper replanning or even online planning at each fraction might reduce this rate. Late GI toxicity after this treatment was negligible and the erectile function preservation rate and the 5 year bRFS was excellent.

\section{Abbreviations}

HDR-BT: High-dose-rate brachytherapy; PD: Prescribed dose; ADT: Androgen deprivation therapy; GU: Genitourinary; GI: Gastrointestinal; bRFS: Biochemical recurrence-free survival; TRUS: Transrectal ultrasound; CT: Computed tomography; MRI: Magnetic resonance imaging; GnRH: Gonadotropin releasing hormone analogue; OAR: Organs at risk; DVH: Dose volume histogram; PTV: Planning target volume; ED: Erectile dysfunction; CTCAE: Common terminology criteria for adverse events; IQR: Interquartile range; IPSS: International prostate symptom score.

\section{Competing interests}

The authors declare that there are no financial disclosures or conflict of interest that could be perceived as prejudicing the impartiality of the research reported.

\section{Authors' contributions}

Each author had participated sufficiently in the work to take public responsibility for appropriate portions of the content. PG and DMA designed the study. PG and SLO performed the statistical analysis. SLO, NC and PG collected the data and together with CAR, BI, GNT and DMA interpreted the data. The manuscript was written by SLO and PG, all other authors helped and finally approved the final manuscript.

\section{Author details}

1'Department of Radiation Oncology, Charité Universitätsmedizin Berlin, Augustenburger Platz 1, Berlin 13353, Germany. ${ }^{2}$ Department of Radiation Oncology with Division of Medical Radiation Physics, Bern University Hospital, Inselspital, Bern, Freiburgstrasse, Bern 3010, Switzerland. ${ }^{3}$ Department of Urology, University of Basel, Spitalstrasse 21, Basel 4031 Switzerland. ${ }^{4}$ Department of Urology, Bern University Hospital, Inselspital, Bern, Freiburgstrasse, Bern 3010, Switzerland.

Received: 31 March 2014 Accepted: 18 May 2014

Published: 28 May 2014

\section{References}

1. Demanes DJ, Martinez AA, Ghilezan M, Hill DR, Schour L, Brandt D, Gustafson G: High-dose-rate monotherapy: safe and effective brachytherapy for patients with localized prostate cancer. Int I Radiat Oncol Biol Phys 2011, 81:1286-1292.

2. Zamboglou N, Tselis N, Baltas D, Buhleier T, Martin T, Milickovic N, Papaioannou S, Ackermann H, Tunn UW: High-dose-rate interstitial brachytherapy as monotherapy for clinically localized prostate cancer: Treatment evolution and mature results. Int J Radiat Oncol Biol Phys 2013, 85:672-678.

3. Yoshioka Y, Konishi K, Sumida I, Takahashi Y, Isohashi F, Ogata T, Koizumi M, Yamazaki H, Nonomura N, Okuyama A, Inoue T: Monotherapeutic high-dose-rate brachytherapy for prostate cancer: five-year results of an extreme hypofractionation regimen with $54 \mathrm{~Gy}$ in nine fractions. Int J Radiat Oncol Biol Phys 2011, 80:469-475.

4. Hoskin P, Rojas A, Lowe G, Bryant L, Ostler P, Hughes R, Milner J, Cladd H: High-dose-rate brachytherapy alone for localized prostate cancer in patients at moderate or high risk of biochemical recurrence. Int J Radiat Oncol Biol Phys 2012, 82:1376-1384.

5. Rogers CL, Alder SC, Rogers RL, Hopkins SA, Platt ML, Childs LC, Crouch RH, Hansen RS, Hayes JK: High dose brachytherapy as monotherapy for intermediate risk prostate cancer. J Urol 2012, 187:109-116.

6. Barkati M, Williams SG, Foroudi F, Tai KH, Chander S, van Dyk S, See A, Duchesne GM: High-dose-rate brachytherapy as a monotherapy for favorable-risk prostate cancer: a phase II trial. Int J Radiat Oncol Biol Phys 2012, 82:1889-1896.

7. Ghilezan M, Martinez A, Gustason G, Krauss D, Antonucci JV, Chen P, Fontanesi J, Wallace M, Ye H, Casey A, Sebastian E, Kim L, Limbacher A: High-dose-rate brachytherapy as monotherapy delivered in two fractions within one day for favorable/intermediate-risk prostate cancer: preliminary toxicity data. Int J Radiat Oncol Biol Phys 2012, 83:927-932.

8. Prada PJ, Jimenez I, González-Suárez H, Fernández J, Cuervo-Arango C, Mendez L: High-dose-rate interstitial brachytherapy as monotherapy in one fraction and transperineal hyaluronic acid injection into the perirectal fat for the treatment of favorable stage prostate cancer: treatment description and preliminary results. Brachytherapy 2012, 11:105-110

9. Ghadjar P, Keller T, Rentsch CA, Isaak B, Behrensmeier F, Stroux A, Thalmann GN, Aebersold DM: Toxicity and early treatment outcomes in low- and intermediate-risk prostate cancer managed by high-dose-rate brachytherapy as a monotherapy. Brachytherapy 2009, 8:45-51.

10. Ghadjar P, Gwerder N, Madlung A, Behrensmeier F, Thalmann GN, Mini R, Aebersold DM: Use of gold markers for setup in image-guided fractionated high-dose-rate brachytherapy as a monotherapy for prostate cancer. Strahlenther Onkol 2009, 185:731-735.

11. Seppenwoolde Y, Kolkman-Deurloo IK, Sipkema D, de Langen M, Praag J Jansen P, Heijmen B: HDR prostate monotherapy: dosimetric effects of implant deformation due to posture change between TRUS- and CT-imaging. Radiother Oncol 2008, 86:114-119.

12. Van den Bergh RC, Roemeling S, Roobol MJ, Aus G, Hugosson J, Rannikko AS, Tammela TL, Bangma CH, Schröder FH: Outcomes of men with screen-detected prostate cancer eligible for active surveillance who were managed expectantly. Eur Urol 2009, 55:1-8.

doi:10.1186/1748-717X-9-122

Cite this article as: Ghadjar et al:: Late toxicity and five year outcomes after high-dose-rate brachytherapy as a monotherapy for localized prostate cancer. Radiation Oncology 2014 9:122.

\section{Submit your next manuscript to BioMed Central and take full advantage of:}

- Convenient online submission

- Thorough peer review

- No space constraints or color figure charges

- Immediate publication on acceptance

- Inclusion in PubMed, CAS, Scopus and Google Scholar

- Research which is freely available for redistribution 